\title{
A Review of Turboelectric Distributed Propulsion Technologies for N+3 Aircraft Electrical Systems
}

\author{
Karen Davies, Patrick Norman, Catherine \\ Jones, Stuart Galloway \\ Institute for Energy and Environment, \\ University of Strathclyde \\ karen.davies@strath.ac.uk
}

\author{
Mark Husband \\ Rolls-Royce Strategic Research Centre, UK
}

\begin{abstract}
In order to minimise the environmental impact of increased air traffic substantial developments in civil aircraft electrical power systems must occur. NASA have set a target to reduce noise by $71 \mathrm{~dB}$, NOx emissions by $80 \%$ and fuel consumption by $60 \%$ for the $N+3$ generation of aircraft entering into service sometime between 2030 and 2035 [1]. Turboelectric Distributed Propulsion (TeDP) is expected to enable these goals to be met. NASA's N3-X concept aircraft comprises gas turbine engines which drive electrical generators and a DC network distributes power to an array of fans, which provide thrust. Interconnection and protection technologies will also be included to achieve desired levels of reliability of supply to the propulsion motors. This paper outlines the architecture of a generic TeDP system, explores its benefits, describes technical challenges that will need to be overcome and discusses the technical implications of implementing TeDP with regards to electrical system power density and safety.
\end{abstract}

\section{Keywords-Turboelectric Distributed Propulsion, N+3}

\section{INTRODUCTION}

In 2011 there were 2.8 billion air travel passengers worldwide [2]. Air traffic grows by approximately 5\% each year and this rate of growth is predicted to continue for the next twenty years [3][4]. In order to minimise the environmental impact of increased air traffic, substantial developments in civil aircraft technologies, in particular the electrical power systems on the aircraft, must occur. In shaping its technology roadmaps, NASA has laid out ambitious goals for noise, NOx emissions, fuel consumption and field length for the next three generations of aircraft, namely $\mathrm{N}+1, \mathrm{~N}+2$ and $\mathrm{N}+3$. These goals are summarised in Table 1.

Several technological concepts have been identified as key to meeting the requirements of these $\mathrm{N}+1,2$ and 3 architectures. These include the complementary Turboelectric Distributed Propulsion (TeDP) and Hybrid Wing Body (HWB) concepts [1]. In a TeDP configuration, electric generators are driven by the gas turbine engines to supply electrical power to multiple electric fans which are distributed across the airframe to provide propulsion. One of the major benefits of an electrical connection between the turbines and the fans is that it acts as a variable ratio gearbox allowing both components to be run at their optimum speed, independent of one another [5].

Other benefits include achieving symmetrical thrust in the event of engine or generator failure and low noise from the low pressure ratio fans. However, a number of key challenges remain in implementing a complex architecture with unproven superconducting technologies whilst minimising the overall weight of the system.

This paper will outline the electrical architecture of a generic TeDP system, explore the benefits of this system and describe the technical challenges that still need to be overcome. The paper will then discuss the technical implications of N3-X aircraft designs which combine both HWB and TeDP technologies, with regards to electrical system stability and safety.

Given the critical nature of the electrical propulsion system to safe flight, strict reliability requirements must be adhered to. However, the failure modes of the TeDP electrical system are as yet not fully known. This paper explores the requirement to characterise these in detail, enabling protection

TABLE I. NASA'S GOALS FOR FUTURE GENERATION SUBSONIC FIXED WING AIRCRAFT

system technology requirements to be determined.

Building on this analysis, different TeDP electrical

\begin{tabular}{|c|c|c|c|}
\hline $\begin{array}{c}\text { Corners of the Trade } \\
\text { Space }\end{array}$ & $\begin{array}{c}\text { N+1 (2015)* } \\
\text { Conventional } \\
\text { Tube \& Wing } \\
\text { (Relative to } \\
\text { B737) }\end{array}$ & $\begin{array}{c}\text { N+2 (2020)* } \\
\text { Unconventio } \\
\text {-nal Hybrid } \\
\text { Wing Body } \\
\text { (Relative to } \\
\text { B777) }\end{array}$ & $\begin{array}{c}\text { N+3 (2025)* } \\
\text { Advanced } \\
\text { Aerospace } \\
\text { Concepts } \\
\text { (Relative to } \\
\text { B737) }\end{array}$ \\
\hline $\begin{array}{c}\text { Noise } \\
\text { (cum below Stage 4) }\end{array}$ & $-32 \mathrm{~dB}$ & $-42 \mathrm{~dB}$ & $-71 \mathrm{~dB}$ \\
\hline $\begin{array}{c}\text { LTO NOx Emissions } \\
\text { (below CAEP 6) }\end{array}$ & $-60 \%$ & $-75 \%$ & $-80 \%$ \\
\hline $\begin{array}{c}\text { Cruise NOx } \\
\text { Emissions } \\
\text { (relative to 2005 best } \\
\text { in class) }\end{array}$ & $-55 \%$ & $-70 \%$ & $-80 \%$ \\
\hline $\begin{array}{c}\text { Aircraft Fuel/Energy } \\
\text { ( }\end{array}$ & $-33 \%$ & $-50 \%$ & $-60 \%$ \\
\hline $\begin{array}{l}* \text { Enabling technologies should reach TRL } \\
\text { for N+1, N+2 and N+3 respectively. } \\
* * \text { Concepts that enable optimal use of } \\
\text { runways) within the metropolitan areas. }\end{array}$ &
\end{tabular}


This paper is a post-print of the paper accepted and published at the 2013 International Universities' Power Engineering Conference, on the $2^{\text {nd }}$ of September 2013, and is therefore subject to IEEE copyright.

systems architectures will be examined and assessed with regards to the balance between system redundancy and safety, as well as weight and complexity.

\section{TURBOELECTRIC DISTRIBUTED PROPULSION}

Conventional aircraft convert the majority of the power generated by the engines into propulsive power. The remaining power is converted into other forms for use in various onboard systems. For example: each engine uses a high pressure compressor to produce pneumatic power which is used for the Environmental Control System (ECS) and Wing Anti-Icing (WAI) system, a mechanical gearbox to drive a central hydraulic pump which is used for flight control actuation and a generator which produces electrical power to supply galley loads, cabin lighting and avionics. Individually these systems have drawbacks. For example, the hydraulic system is heavy and inflexible, and it can be difficult to detect a leak in the pneumatic system[6]. Also, they have become more advanced, integration has become more complex. For ease of integration and maintenance it would be advantageous to use one type of non-propulsive power for all secondary systems.

Electrical power is the only type of power that could be used for all systems, and it is this concept which forms the basis of the more-electric aircraft (MEA) [6]. Evidence of the trend towards MEA can already be seen within Airbus and Boei ng

Fig. 1. Comparison of a conventional tube-and wing aircraft and the more-electric B787

in lower maintenance efforts and costs, as well as better reliability, as the electrical system comprises fewer components and is less complex to repair than the previous pneumatic system [7].

Continuing this trend, the all-electric aircraft concept looks to further exploit the potential benefits of electrical systems for aircraft propulsion. Today's aircraft utilise turbofan engines to provide propulsive power. The turbine stages of these engines are more effective when running at a higher speed whilst; the propulsive fans are more efficient, and quieter, at lower speeds. With a common shaft connecting these components, there is often compromise to run at the combined optimum speed [5].

One option for overcoming this limitation is through the utilisation of TeDP. The electrical connection employed between the turbines and the fans acts as a variable ratio gearbox so that both components can be run at their optimum speed, independent of one another [5].

This aspect is a key feature of NASA's N3-X concept aircraft, which proposes the implementation of TeDP on a HWB airframe, as shown in Fig. 2. and Fig. 3 [8]. The HWB airframe offers a high lift to drag ratio, facilitating lower fuel burn during flight. The engines are mounted on the upper aft section of the aircraft, shielding some of the noise from the ground [9].

Mounted at the tip of each wing is a gas turbindraulic engine flight control actuators

core, each powering two superconducting electrical generators, with each plant capable of providing 22.4 MVA. The AC power from the generators is converted to DC and distributed via four central main distribution buses and a network of superconducting cables. To supply AC power to

aircraft, the A380 and B787 respectively. For example, the B787 utilises a "no-bleed electrical architecture", meaning that operations previously powered by the pneumatic system are now electrically powered (as illustrated in Fig.1.). This results
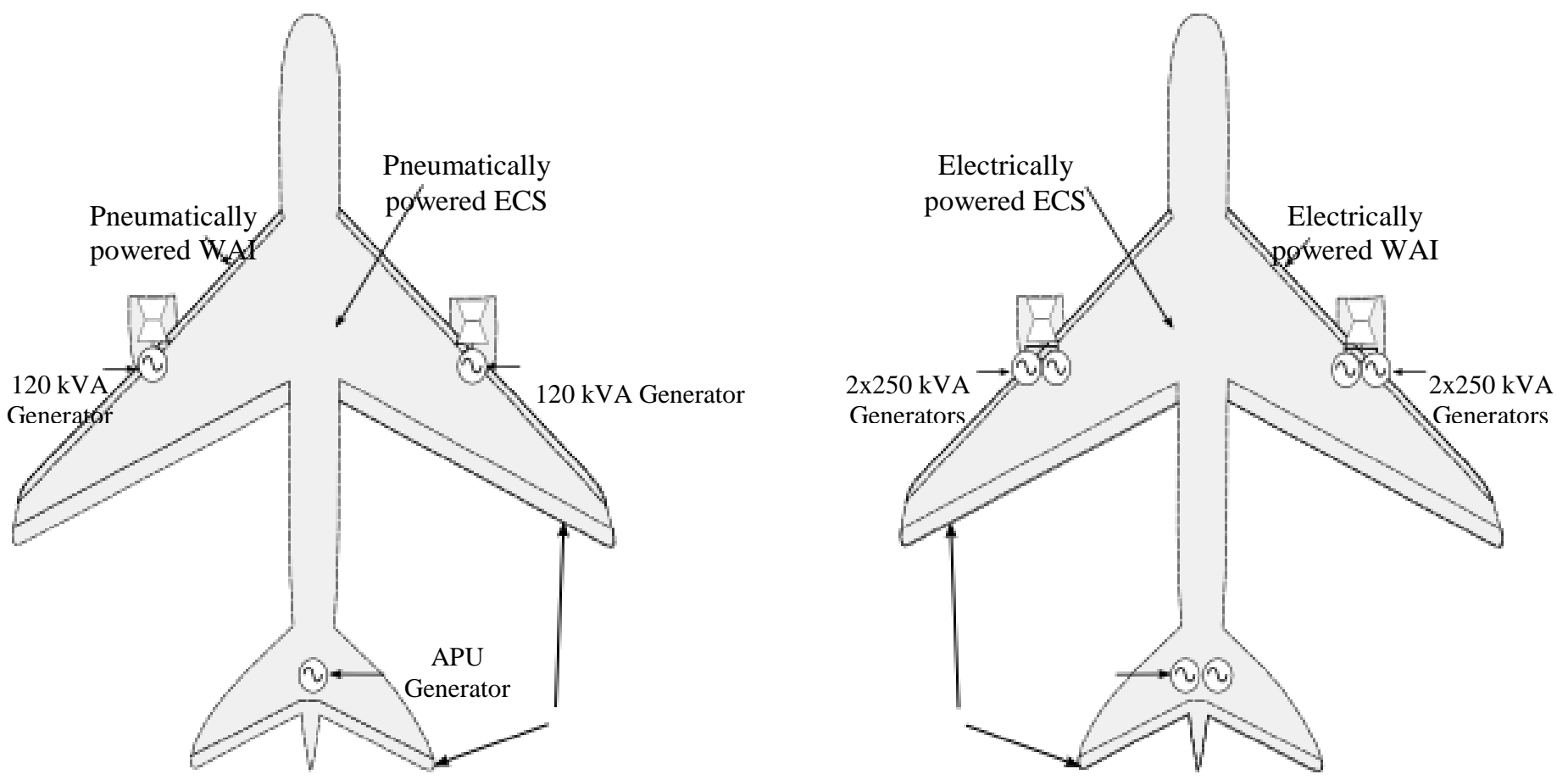
This paper is a post-print of the paper accepted and published at the 2013 International Universities' Power Engineering Conference, on the $2^{\text {nd }}$ of September 2013, and is therefore subject to IEEE copyright.

14 superconducting-motor-driven fans, which are placed at the aft of the aircraft, this DC power is converted back to variable frequency AC. A candidate electrical architecture of the N3-X is shown in Fig. 4. The distribution buses and motors are connected in such a way that an engine or generator failure will not result in any asymmetrical thrust. Additionally, this architecture may also include interconnection, fast acting breakers/contactors and fault current limiting technologies in order to achieve desired levels of reliability of supply to the propulsion motors. The architecture may also feature nonpropulsive electrical loading (i.e. ECS, WAI and galley loads), although these may be supplied by independent nonsuperconducting generators [5].

The following sections of this paper describe some of the major benefits of a TeDP/HWB aircraft over a conventionally powered tube and wing aircraft, and discuss the pertinent technical challenges faced in its development.

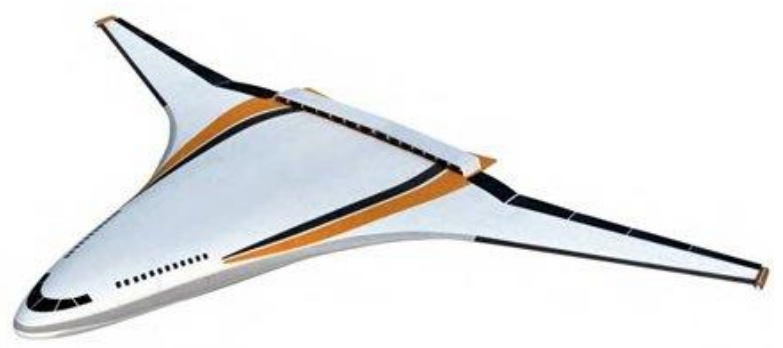

Fig. 2. NASA's N3-X concept aircraft, which combines a HWB airframe with TeDP.

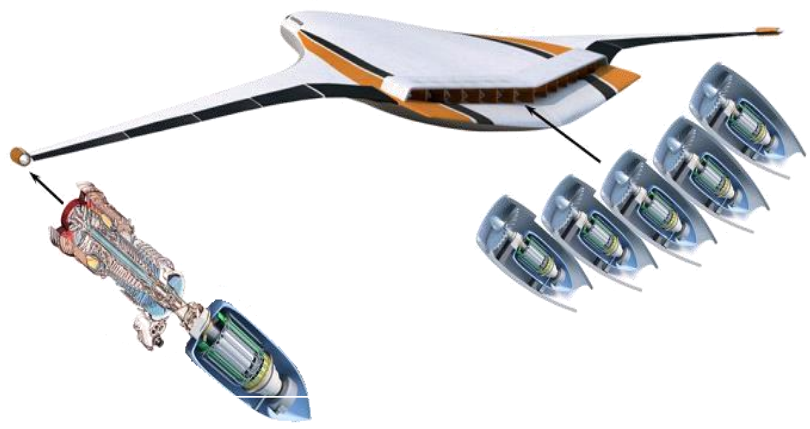

Fig. 3. Wing-tip mounted superconducting generators supply an array of superconducting motors via a DC bus

\section{BENEFITS OF A TEDP/HWB AIRCRAFT}

\section{A. Electrical power system}

\section{1) Decoupling}

Replacing the mechanical connection between the engine and the thrust producing device with an electrical connection has two benefits: First, both devices can be placed wherever is most beneficial to the aircraft as a whole. Secondly, and more importantly in the context of this paper, the speed of the thrust producing device is no longer dependent on the speed of the engine turbine shaft. Both devices can be run at their most

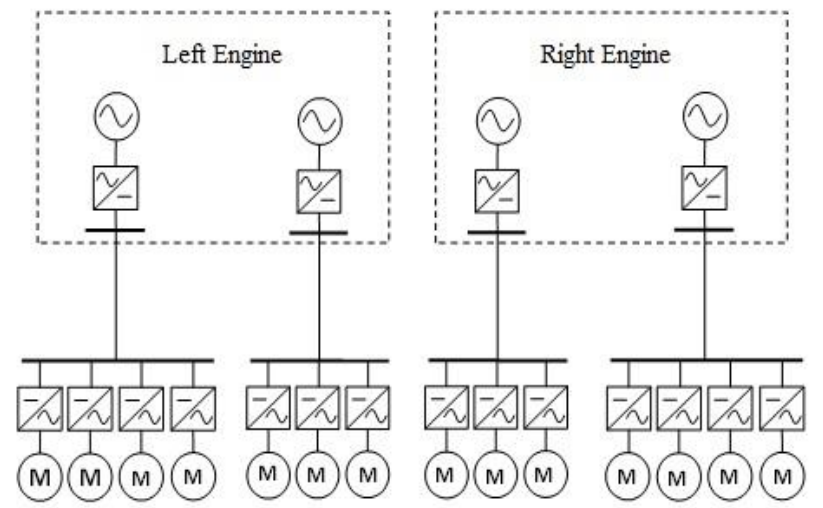

Fig. 4. Electrical architecture of the N3-X propulsion system.

efficient speeds, with the electrical connection effectively acting as a variable gearbox [9]. By decoupling the devices the thermal efficiency of the gas turbine is separated from the propulsive efficiency, indicated by the bypass ratio, allowing both to be designed for the optimal efficiency.

2) Symmetric and asymmetric fan thrust

The flexibility introduced by decoupling the engines from the fans combined with the adoption of multiple distributed fans allows for additional flexibility of flight control. Changing the power distribution across the fan array can result in either symmetrical or asymmetrical thrust. In the event of an engine or generator fault symmetrical thrust would be used to maintain control. Failure modes, such as engine failure during take-off, are supported by a TeDP design as the overall system margin involved is reduced. Also, this design reduces the overall drag and structural weight requirements. Asymmetrical thrust would be used for yaw control [4].

Conversely, the motors can be physically arranged so as not to result in asymmetrical thrust in the event of either an engine or a generator failure.

3) Non-propulsive power provision

In addition to providing the power required for the propulsion system, the generators could be used to provide electrical power for the non-propulsive systems of the aircraft, such as WAI and ECS.

\section{B. Additional benefits}

Although the focus of this paper is on the electrical power system, there are many additional non-electrical benefits which are resultant of the electrical power system or the close integration between the airframe and the propulsion system, some of which are listed below.

\section{1) Boundary layer ingestion (BLI)}

The efficiency of the propulsive system can be improved by either reducing the specific thrust, which is achieved by increasing the bypass ratio of the engine, or by reducing the inlet velocity, which is achieved with BLI [10]. The 
This paper is a post-print of the paper accepted and published at the 2013 International Universities' Power Engineering Conference, on the $2^{\text {nd }}$ of September 2013, and is therefore subject to IEEE copyright.

positioning of the fan inlets at the aft of the aircraft allows for the ingestion of the slow-moving boundary layer, resulting in a reduction in overall drag which leads to reduced fuel consumption [11].

2) Noise reduction

The introduction of low pressure ratio fans on the upper aft section of the aircraft will lower the aircraft noise signature as the airframe will shield the "downward propagation". This benefit is a result of the increased emphasis placed on airframe propulsion integration by NASA in the design process. There will also be a reduction in noise experienced by passengers in the cabin, as the gas turbine engines will be mounted on the wing tip, rather than next to the fuselage as with conventional aircraft [4].

\section{CHALLENGES FACING THE IMPLEMENTATION OF THE N3-X ELECTRICAL NETWORK}

\section{A. Electrical Power System}

\section{1) Superconducting architecture}

Integral to the success of TeDP aircraft is the development of reliable, compact and lightweight superconducting technologies, such as generators, motors, converters, protection devices and cables. In order for TeDP to become a practical option for future generation aircraft, superconducting generators and motors must have considerable power densities. The power density of today's gas turbine engines lies within the range $3-8 \mathrm{~kW} / \mathrm{kg}$ [5]. Ongoing studies have shown that part-superconducting generators and motors have the capability to reach these power densities, however only fully superconducting machines will be able to surpass these levels. NASA's URETI program [5] has predicted that power densities of $66 \mathrm{~kW} / \mathrm{kg}$ for fully superconducting generators and $40 \mathrm{~kW} / \mathrm{kg}$ for fully superconducting motors may be achievable.

Oversizing of components will be required in a TeDP system in order to maintain specific thrust levels in the event of a motor, network or generator failure[12], the extent of which is critical to the competitiveness of TeDP. This oversizing serves to effectively reduce the overall power density of the TeDP system. However, through informed electrical architecture design, it may be possible to minimize the extent of this oversizing.

From [13] it can be seen that the expected power densities associated with superconducting cables and protection devices are greater than the corresponding power densities associated with superconducting generators and propulsion motors. Hence, the weight of the overall electrical power system will be more sensitive to the sizing of the generators and propulsion motors than the cabling and protection devices. Therefore additional redundancy in the form of extra cabling may be favourable if it facilitates a reduction in the oversizing of the other system components.

To illustrate this aspect, Table II summarises the attributes of four candidate electrical architectures for the N3-X concept aircraft proposed in [9]. Each of the four architectures utilises four generators and fourteen propulsors. However they vary slightly in terms of levels of redundancy and interconnection.

The first architecture presented in [12] has no cabling redundancy or interconnection between buses. This architecture minimizes the disruption caused by any single failure on the remaining network components but requires significant oversizing of components as there are no redundant power supply paths to the propulsion motors. The impact on this oversizing is apparent in the projected weight of the architecture.

The second architecture proposed by the authors in [9] utilises a normally open bus tie between two of the central buses. This architecture requires a more complex protection and control system to fully exploit this redundancy, but offers potential savings in mass when compared with the first.

TABLE II. SUMMARY OF TeDP CANDIDATE ARCHITECTURES

\begin{tabular}{|c|c|c|}
\hline Architecture Summary & $\begin{array}{c}\text { Summary of key } \\
\text { component ratings }\end{array}$ & $\begin{array}{c}\text { Projected } \\
\text { Total Mass }\end{array}$ \\
\hline $\begin{array}{c}\text { Radial - no cabling } \\
\text { redundancy or } \\
\text { interconnection between } \\
\text { buses }\end{array}$ & $\begin{array}{r}\text { Generators: } 2 \times 12.8 \mathrm{MVA} \\
2 \times 9.6 \mathrm{MVA}\end{array}$ & $5080 \mathrm{~kg}$ \\
\hline $\begin{array}{c}\text { Motors: } 14 \times 3.2 \mathrm{MVA} \\
\text { Radial with bus ties }\end{array}$ & $\begin{array}{c}\text { Generators: } 2 \times 13.44 \mathrm{MVA} \\
2 \times 8.96 \mathrm{MVA} \\
\text { Motors: } 14 \times 2.24 \mathrm{MVA}\end{array}$ & $4320 \mathrm{~kg}$ \\
\hline $\begin{array}{c}\text { Three bus multi-feeder } \\
\text { system }\end{array}$ & $\begin{array}{c}\text { Generators: } 4 \times 11.2 \mathrm{MVA} \\
\text { Motors: } 14 \times 1.86 \mathrm{MVA}\end{array}$ & $4130 \mathrm{~kg}$ \\
\hline High-redundancy system & $\begin{array}{c}\text { Generators: } 4 \times 11.2 \mathrm{MVA} \\
\text { Motors: } 14 \times 1.86 \mathrm{MVA}\end{array}$ & $4115 \mathrm{~kg}$ \\
\hline
\end{tabular}

The third architecture proposed is a three bus multi-feeder system, where each propulsion motor is fed from two separate buses. This allows for a rerouting of power in the event of a fault or component failure, reducing the oversizing requirements for propulsion motors. As this architecture relies on different rerouting schemes for different fault scenarios, it is more complex than the previous two architectures, but offers further reductions in mass.

The final, and most complex architecture proposed by the authors in [9] utilises redundancy in the wing transmission as well as in the distribution buses and feeders. As the high level of redundancy decreases the power requirements of the propulsion system components, this architecture is also the lightest of the four considered.

\section{2) Characterising failure modes and protection}

A superconducting network will have zero resistance (in normal operation) and a much lower inductance than a nonsuperconducting network. These characteristics facilitate rapid fault propagation throughout a network and create a risk of the 
This paper is a post-print of the paper accepted and published at the 2013 International Universities' Power Engineering Conference, on the $2^{\text {nd }}$ of September 2013, and is therefore subject to IEEE copyright.

system quenching, causing a resultant loss of supply to the propulsion motors. It is hence likely that the operating requirements for the electrical architecture protection systems will be very stringent. The ability of the protection systems to meet these requirements will impact on the architectural choices available in the design of TeDP systems and hence ultimately determine the competitiveness of the TeDP concept when compared to more conventional propulsion systems.

Early research in this area suggests that fault current limiters may be a key protection technology in TeDP systems, to both limit the damage caused by electrical energy at the point of fault and also to minimise the ratings and mass of complementary circuit breaker technologies [9]. However, the limitation of fault current increases the difficulties associated with fault detection and location [13], requiring the development and deployment of novel fault detection algorithms.

\section{3) Cooling system}

In order to keep the superconducting network at the required temperature a cryogenic cooling system will have to be utilised, which will add weight to the overall system and add to the power requirements of the electrical system. The integration of these two systems is imperative, as their reliability is vital to the safety of the aircraft. In this manner, a fault in the cooling system could result in the quenching of the superconducting network, causing the supply of power to the propulsion motors to subsequently fail.

\section{CONCLUSION}

In order to curb the adverse effects of increased air traffic on the environment, in terms of NOx emissions, noise and fuel consumption, NASA have set out ambitious targets for the next three generations of aircraft. TeDP has been identified as a promising technology to help meet the targets set for the $\mathrm{N}+3$ generation, and NASA have developed the N3-X concept aircraft which combines TeDP with an HWB airframe in order to capitalise on the benefits of both new technologies. There are many expected advantages to the N3-X architecture when compared with a conventional tube-and-wing aircraft, one of which is the decoupling of the engine and the propulsors. This allows greater flexibility for the system, as both components can be operated at their most efficient speed. However there are still a great number of challenges facing implementation of the N3-X, including the development of fully superconducting machines with high power densities, reliable interconnected network architectures and effective protection systems for compact DC superconducting networks. This paper reviews these and evaluates their criticality in shaping the competitiveness of the TeDP concept.

\section{ACKNOWLEDGMENT}

This work has been carried out as part of the Rolls-Royce UTC programme.

\section{REFERENCES}

[1] J. L. Felder, H. D. Kim, and G. V. Brown, "Turboelectric Distributed Propulsion Engine Cycle Analysis for HybridWing-Body Aircraft," presented at the 47th AIAA Aerospace Sciences Meeting, 2009.

[2] “2012 Annual Review,” IATA, Jun. 2012.

[3] "Navigating the Future," Airbus, France, Aug. 2012.

[4] "Current Market Outlook 2012-2031," Boeing, Seattle, Washington, 2012.

[5] C. A. Luongo, P. J. Masson, T. Nam, D. Mavris, H. D. Kim, G. V. Brown, M. Waters, and D. Hall, "Next Generation MoreElectric Aircraft: A Potential Application for HTS Superconductors," IEEE Trans. Appl. Supercond., vol. 19, no. 3, pp. $1055-1068$, Jun. 2009.

[6] J. A. Rosero, J. A. Ortega, E. Aldabas, and L. Romeral, "Moving towards a more electric aircraft," IEEE Aerosp. Electron. Syst. Mag., vol. 22, no. 3, pp. 3 -9, Mar. 2007.

[7] M. Sinnett, "787 No-Bleed Systems: Saving Fuel and Enhancing Operational Efficiencies," Boeing, 2007.

[8] R. Del Rosario, G. Follen, R. Wahls, and N. Madavan, "Subsonic Fixed Wing Project Overview of Technical Challenges for Energy Efficient, Environmentally Compatible Subsonic Transport Aircraft," presented at the AIAA Aerospace Sciences Meeting, Nashville, TN, Jan-2012.

[9] H. D. Kim, G. V. Brown, and J. L. Felder, "Distributed Turboelectric Propulsion for Hybrid Wing Body," presented at the International Powered Lift Conference, 2008.

[10] H.-J. Steiner, A. Seitz, K. Wieczorek, K. Plotner, A. T. Isikveren, and M. Hornung, "Multi-disciplinary design and feasibility study of distributed propulsion systems," presented at the 28th International Congress of the Aeronautical Sciences, 2012.

[11] H. D. Kim, "Distributed Propulsion Vehicles," presented at the 27th International Congress of the Aeronautical Sciences.

[12] M. J. Armstrong, C. A. H. Ross, M. J. Blackwelder, and K. Rajashekara, "Trade Studies for NASA N3-X Turboelectric Distributed Propulsion System Electrical Power Architecture," SAE Int J Aerosp, vol. 5, no. 2, Dec. 2012.

[13] M. J. Armstrong, C. A. H. Ross, M. J. Blackwelder, and K. Rajashekara, "Propulsion System Component Considerations for NASA N3-X Turboelectric Distributed Propulsion System," SAE Int J Aerosp, vol. 5, no. 2, Dec. 2012. 